\title{
SLIP IN SINGLE CRYSTALS OF ICE
}

\author{
By C. J. Readings* and J. T. Bartlett ${ }^{*}$
}

(Department of Cloud Physics, Imperial College of Science and Technology, South Kensington, London S.W.7, England)

\begin{abstract}
Austract. Rectangular specimens of ice $(c .5 \mathrm{~cm} \times 2 \mathrm{~cm} \times 0.5 \mathrm{~cm})$ were cut from large single crystals (c. $10 \mathrm{~cm} \times 5 \mathrm{~cm}^{2}$ ) grown from pure water by a modified Bridgman technique. When these specimens were deformed under controlled conditions. slip lines which were predominantly parallel to the basal plane became visible. In some cases short, perpendicular segments were also seen which can be interpreted as evidence for cross-slip in ice. Measurements of slip-band spacings were made on silvered "lormvar" replicas of some deformed crystals. These measurements showed that "coarse" slip occurred when the resolved shear stress on the basal plane, $\sigma$, was greater than about 0.2 bars, and that the average thickness of the slip lamellae. $d(\mathrm{~cm})$ was approximately given by Wakahama's relationship. $(\sigma-0.2) d-0.45 \times 10^{-3}$. At lower stresses "fine" slip occurred. and the relationship between the average thickness of the lamellac and the resolved shear stress was more adequately described by Taylor's formula, od $7.2 \times 10$ \%. It is. however, possible that both coarse and fine slip occurred at higher stresses, but that the fine slip was then below the limit of resolution.

Résumí. Glissement dans des monocristaux de glace. Des échantillons de glace rectangulaires (environ $5 \times 2 \times 0.5 \mathrm{~cm}$ ) ont été coupés dans de larges monocristaux (environ $10 \mathrm{~cm} \times 5 \mathrm{~cm}^{2}$ ) issus d'une eau pure par la technique de Bridgman modifiée. Lorsque ces échantillons étaient déformés dans des conditions controlées. des lignes de glissement principalement parallèles au plan de base devenaient visibles. Dans quelques cas. des segments courts perpendiculaires devenaient aussi visibles ce qui peut ère interprèté comme l'évidence d'un glissement dévié dans la glace. Des mesures des espacements entre les bandes de glissement ont été faites sur des repliques argentées "lormvar" de quelques cristaux déformés. Ces mesures ont montré que le "gros" glissement a lieu lorsque la tension de cisaillement sur le plan de base $\sigma$ était plus grande que 0.2 bar. et que l'épaisseur moyenne de la lamelle de glissement $d(\mathrm{~cm})$ était approximativement donnée par la relation de Wakahama $(\sigma-0.2) d=0.45 \times 10^{-3}$. Pour des contraintes plus faibles, un glissement "fin" avait lieu. et la relation entre l'épaisseur moyenne de la lamelle et de la contrainte de cisaillement était mieux décrite par la formule de Taylor od 7.2 to 5 . Il est cependant possible que les deux glissements "fin" "et "gros" ont lieu pour des contraintes plus fortes, mais que le glissenent "lin" était dans ce cas en-dessous de la limite de résolution.
\end{abstract}

Zusammenfassunc. Gleiten in Einkristallen ion Eis. Aus grossen Eis-Einkristallen $\left(10 \mathrm{~cm} 5 \mathrm{~cm}^{2}\right)$, die aus reinem Wasser nach einer modifizierten Bridgman-Technik gezogen worden waren. wurden quaderförmige Eisproben $(5 \mathrm{~cm} \times 2 \mathrm{~cm} \times 0.5 \mathrm{~cm})$ geschnitten. Bei kontrollierter Verformung dieser Proben wurden Gleitlinien sichtbar, die vorwiegend parallel zur Grundlläche verlielen. In einigen Fallen wurden kurze Teillinien senkrecht dazu beobachtet, die als Beweis für ein Quergleiten des Eises gedeutet werden können. Die Abstande der Gleitlinien wurden in versilberten "Formvar"-Nachbildungen von einigen deformierten Kristallen ausgemessen. Diese Messungen zeigten dass "grobes" Gleiten auftrat. wenn die wirksame Scherspannung $a$ auf die Grundfläche grösser als etwa 0.2 bar war. und dass die mittlere Dicke $d(\mathrm{~cm})$ der Gleitschichten annähernd der Beziehung von Wakahama $(\sigma-0,2) d=0.45 \times 10^{-3} \mathrm{entsprach}$. Bei niedrigeren Spannungen trat "feines" Gleiten ein; die Beziehung zwischen mittlerer Lamellendicke und Scherspannung wird dann besser durch laylor's Formel $\sigma d=7,2 \times 10^{-3}$ beschrichen. Es ist jedoch möglich. dass sowohl grobes als auch feines Gleiten bei höheren Spannumgen auftrat, dass aber dann das feine Gleiten unterhalb der Auflösungsgrenze lag.

\section{INTRODUCTION}

Physicists and glaciologists have been interested in the mechanical properties of ice for a long time. Amongst the earliest experiments on the deformation of ice were those performed by McConnel and Kidd (1888) and by McConnel (1890, 1891), who found that single crystals of ice deformed like a pack of cards and also observed that the rate of deformation tended to increase with time and temperature. These early observations have since been confirmed repeatedly by other workers using a variety of different techniques. However, most experiments on the deformation of ice have used natural polycrystalline specimens since the investigators were concerned with engineering problems, whereas for the physicist the deformation of pure single crystals provides a necessary first step towards understanding the mechanisms involved.

Experiments performed on single crystals by Glen and Perutz (1954) showed that slip occurred almost exclusively on the basal plane and that there was no observable preferred

* Present address: Meteorological Office, London Road, Bracknell, Berkshire. England. 
glide direction. Steinemann (1954) also investigated the flow law for single crystals and he too could find no evidence for a preferred glide direction or for non-basal slip, even when he clamped his specimens so that basal glide was prevented.

One of the most interesting investigations into the deformation of single crystals was made by Nakaya ( $1958[\mathrm{a}]$, [b]) who used rectangular bars cut from the large single crystals (often $30 \mathrm{~cm}$ long) calved from the Mendenhall Glacier in Alaska. He deformed these bars by bending them and studied the betaviour of specimens cut in many different orientations. His work clearly demonstratcd that ice behaves like a stack of papers parallel to the luasal plane and that deformation takes place by gliding betwcen the "papers". He also showed that specimens bent about the $c$-axis are extremely rigid.

In the present series of experiments, single crystals of known purity were grown in the laboratory and deformed by compression. The mechanism of deformation was studied by combining three tcchniques: direct observation of thc surface, production of plastic replicas and observations of the crystals in polarized light.

In this paper, the results of our direct observations and the appearance of the plastic replicas will be discussed. The new effccts found with polarized light will be discussed elsewhere.

\section{Experimental Techniques}

Groweth of single crystals

Large single crystals of ice $\left(c .10 \mathrm{~cm} \times 5 \mathrm{~cm}^{2}\right)$ were grown by a Bridgman technique, as described by Jaccard (1959), but with several important modifications.

The crystals were grown in a flexible nylon tube which allowed for the expansion on freering. 'This tube was fitted with a "perspex" (polymethyl methacrylate) cap (Fig. I) in which a seed crystal could be formed after the tubc and its cap had been washed thoroughly and filled with very pure water (resistivity $c .10^{7} \Omega \mathrm{cm}$ ) which was obtained by passing distilled water through an ion exchange column. Care was taken to exclude bubbles of air from the tube and the water was then frozen quickly in polycrystalline form before actually growing single crystals. In this way the amount of dissolved gas was kept to a minimum.

Single crystals were grown by lowering the nylon tube into a cold bath (at about $-25^{\circ} \mathrm{C}$ ) situated in a refrigerator which kept the ambient temperature at about $-10^{\circ} \mathrm{C}$. $\mathrm{A}$ small heater made of Kumunal wire was placed on an asbestos sheet over the cold bath in order to melt the polycrystalline ice. It also allowed a controlled temperaturc gradient to be maintained across the growing interface of the single crystal.

For convenience three specimens were lowered into the cold bath at the same time at a rate of about $\mathrm{I} \mu \mathrm{m} / \mathrm{s}$, which meant that it took about two days 10 grow useful crystals. Each specimen was viewed between crosscd polarizers on a specially designed universal stage (private communication in 1964 from Dr G. P. Rigsby,) to ensure that it was a single crystal and in practice about two-thirds of the specimens were found to be satisfactory. (The same universal stage was also used to find the orientation of the optic axis.)

At the beginning of this work, we used industrial methylated spirit as the refrigerant in the cold bath, following Jaccard's practice of using ethyl alcohol. However alcohol has a high vapour pressure and as it was feared that some vapour might be diffusing through the nylon or leaking through the scal at the top of the tube and dissolving in the water, some of the single crystals preparcd in this way were analysed by Dr H. $\Lambda$. C. Montgomery to determine the concentration of organic carbon in them (Montgomery and Thom, 1962). He found that they contained I2 p.p.m. by weight of organic carbon, compared with o.I p.p.m. in the original purc water. We therefore decided to replace the alcohol by commercially available white paraffin (usually called kerosene in the United States) which has much lower vapour pressure and is almost insoluble in water. Linfortunately a thin film of paraffin formed over all 
the apparatus dipping into the cold bath, and analysis revealed that the organic carbon content of the crystals was still greater than ro p.p.m.

As a result of this experience we decided to replace the organic refrigerant by a eutectic solution of calcium chloride in water which can be cooled to about $-55^{\circ} \mathrm{C}$ before it freezes. The crystals were now found to contain only 2.3 p.p.m. of organic carbon and this residual probably comes from the plasticizer used in the nylon tubing. A flame test showed that there was less than 1 p.p.m. of calcium in them and therefore crystals grown in this way were used in the rest of our experiments.

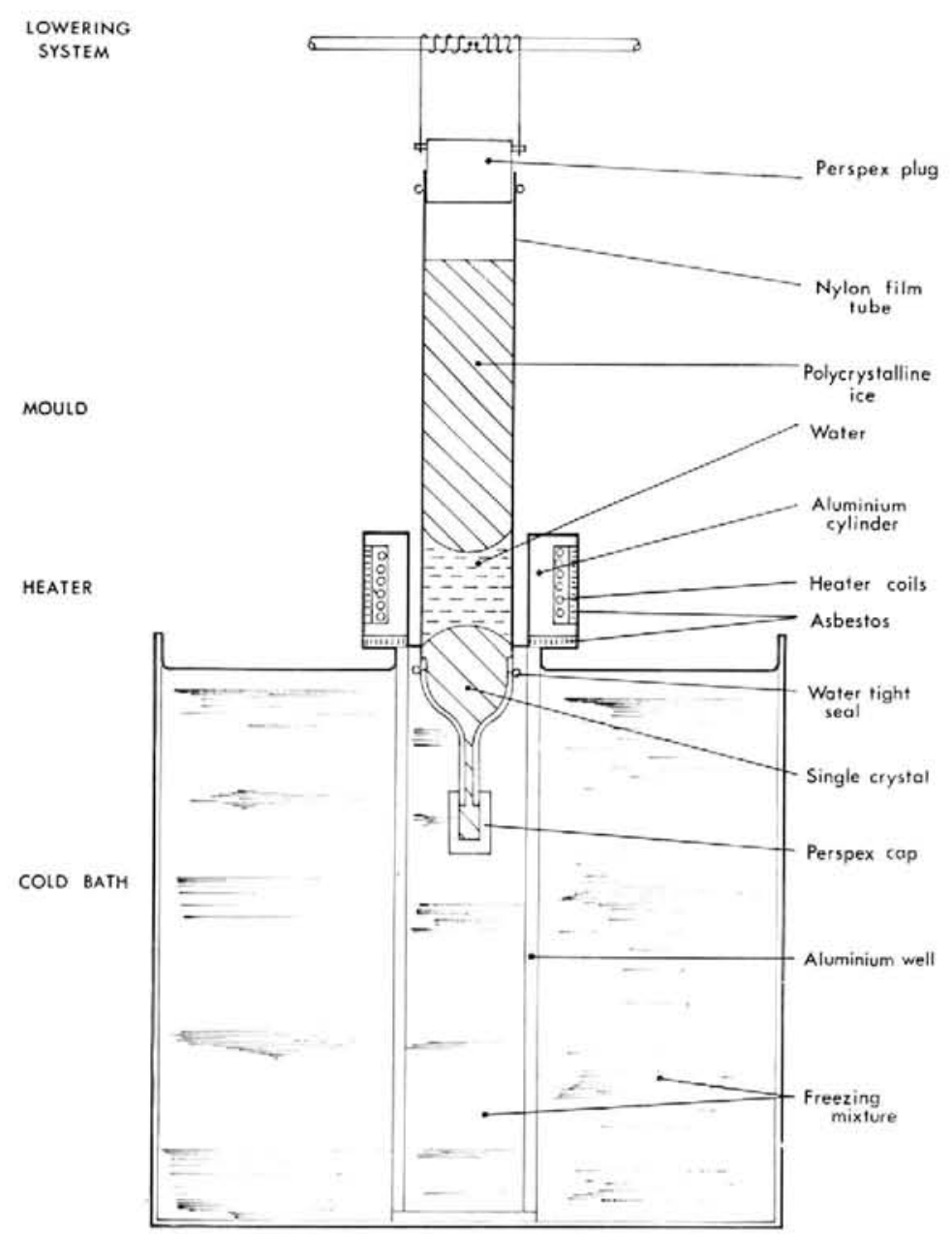

Fig. 1. Apparatus for growing large single crystals of ice.

Shaping of specimens

Rectangular specimens (c. $5 \mathrm{~cm} \times 2 \mathrm{~cm} \times 0.5 \mathrm{~cm}$ ) were required for the deformation experiments and these had to be cut from the larger cylindrical ice crystals produced by the growth frame. Obviously it was important to keep the residual strain and the concentration of dislocations to a minimum when preparing the specimens and so we decided to avoid all mechanical cutters and to melt the crystals to shape. 
The large crystals were first cut to about the right size with a cutter made of Kurnunal heating wire. After this the crystal was roughly shaped on one side by melting it with a warm brass block which had a rectangular groove of the appropriate size cut in it. When the specimen had almost reached the required size, the brass block was cooled to just above 0 C $\mathrm{C}$ and placed in contact with the specimen again. At this stage only a thin film of water formed between the specimen and the brass block. After taking care to eliminate any trapped air bubbles, the brass block was allowed to cool slowly, impressing its shape on to the spccimen. The film usually refroze with exactly the same orientation as the rest of specimen and became indistinguishablc from it.

Any excess ice was then melted away and the other side of the crystal was treated in a similar way (but using a glass slide instead of the brass block) to give a specimen of the required size and shape. As a rule four specimens could be obtained from cach of the large single crystals, two of which were identical and could be used for making comparisons.

Once they were prepared, the specimens were usually stored in paraffin in order to prevent evaporation and kept at a temperature just below $0^{\circ} \mathrm{C}$ until they wcre required.

\section{Stress apparatus}

In all of our experiments the crystals were deformed by compression under a constant load in a cold room at -4 "C. Each end of the rectangular specimens was frozen into a small metal cup with a knife edge fixed to it, and these knife edges were then located between a loaded beam and a fixed base (see Fig. 2) so that the force on the specimen was constant unless the deformation was very largc.

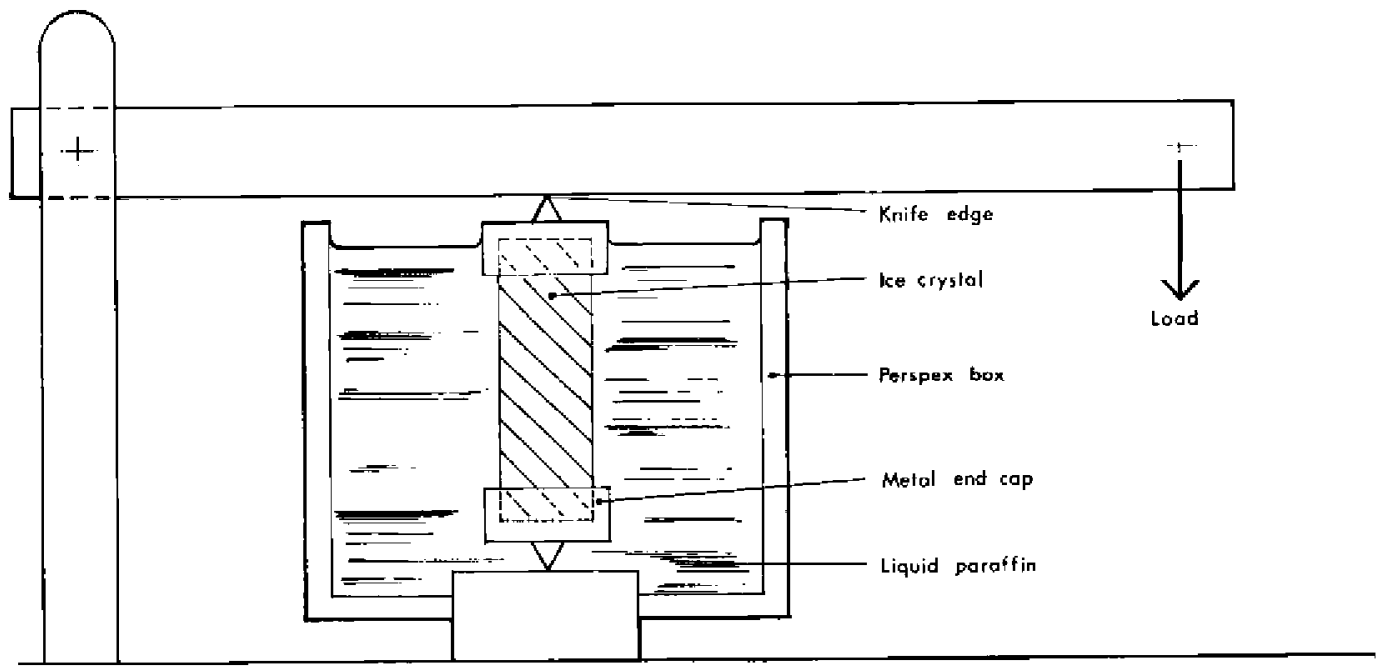

Fis. 2. Apparalus for compressing single crystals of ice.

In one piece of apparatus the specimens wcre mounted between crossed polaroids so that any changes of oricntation could be detected easily. In this case the specimens were viewed through a low-power microscope with a large working distance and by adjusting the lamp and condenser system behind the specimen it was possible to see slip lines and other surface fcatures. The optical arrangement is shown schematically in Figure 3 .

Unfortunately ice has rather a high vapour pressure at the tcmperature of our experiments (4-4 mbar at $-4(\mathrm{C})$ and the specimen cvaporated so rapidly in the relatively dry air circulating in the cold room that any surlace features quickly disappeared. Wo found that the best way to overcome this difficulty was to deform each spccimen under paraffin, as this did not. 
appear to have any adverse effects. The paraffin was contained in a box with perspex sides and base and with strain-free glass windows front and back which were attached to the rest of the box by a special sealing compound.

Since we could not achieve a sufficiently high magnification to observe the fine details of slip bands with this arrangement, we also attempted to deform some specimens on the stage of a microscope. In this experiment the specimens were just covered with paraffin in a shallow dish on the stage of the microscope. However, it was not possible to see any interesting detail and this was probably because the surface was affected by the slight, but unavoidable, movement of the paraffin in the dish.

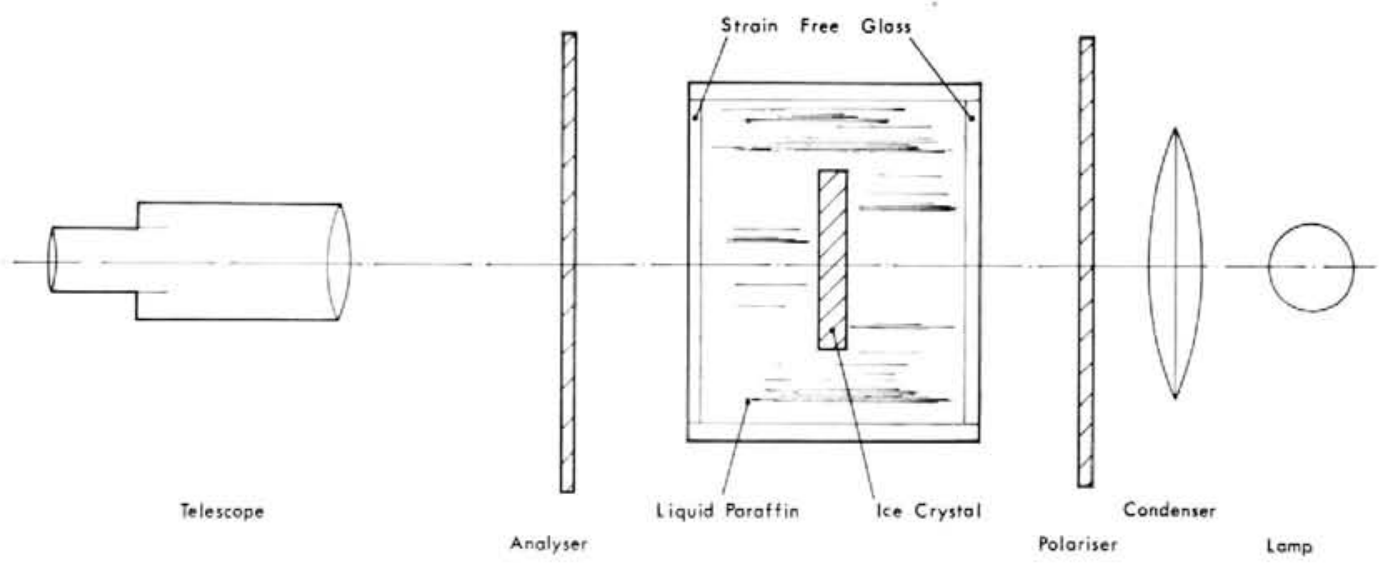

Fig. 3. Plan vicu of stress apparatus showing the optical arrangement for viezing deformed ice coystals.

We therefore decided to try to produce "formvar" replicas of the surface following the method introduced by Schaefer (1946). The difficulty with this procedure is that ice dissolves slightly in a solution of "formvar" in ethylene dichloride. In fact such a solution has been used by a number of workers to etch the surface of ice crystals (e.g. Muguruma, 1963). Thus it is clearly unsatisfactory to deform specimens in the solution when attempting to reveal the detailed surface structure. On the other hand, removing deformed specimens from the stress apparatus and dipping them into the solution is also liable to disturb the surface features.

These difficulties were overcome by first dipping the undeformed specimen into paraffin and then allowing it to drain until only a thin film of paraffin remained on the surface. This protected the surface so that the specimens could then be safely deformed in a cell containing a solution of 6 per cent "formvar" in ethylene dichloride. When the specimen had been deformed sufficiently (usually after a few days at constant load), it was removed from the cell and the excess "formvar" solution allowed to drain off. The remaining thin film soon hardened in contact with the air and could then be separated from the ice in the usual way. Most of the replicas were aluminized and then examined under the microscope. A typical example of such a replica is shown in Figure 4.

\section{OBSERVATIONS}

\section{Slip traces}

Previous experimenters found that ice deforms predominantly by slip on the basal plane. It is therefore not surprising to find that the most obvious feature of ice crystals which have been compressed by about 1 per cent is a series of slip bands parallel to the trace of the basal plane on the surface of the specimen. Typical examples of these bands are shown in Figures 4 
and 5. Comparing the two photographs gives a clear idea of the difference in resolution that can be obtained from a plastic replica of the surface (Fig. 4) and by direct observation (Fig. 5).

It is apparent from these photographs that the spacing of the slip bands is not a constant and that the bands themselves are not all equally prominent. Moreover there was no apparent change in the spacing of the slip bands during compression, only an increase in their promi-

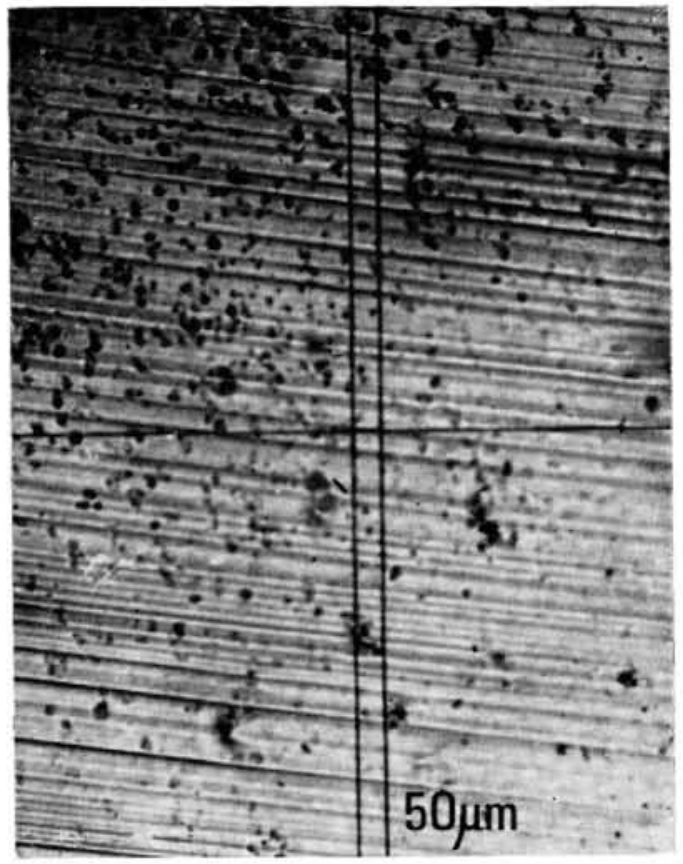

Fig. 4. Silvered replica of the surface of a deformed ice crystal.

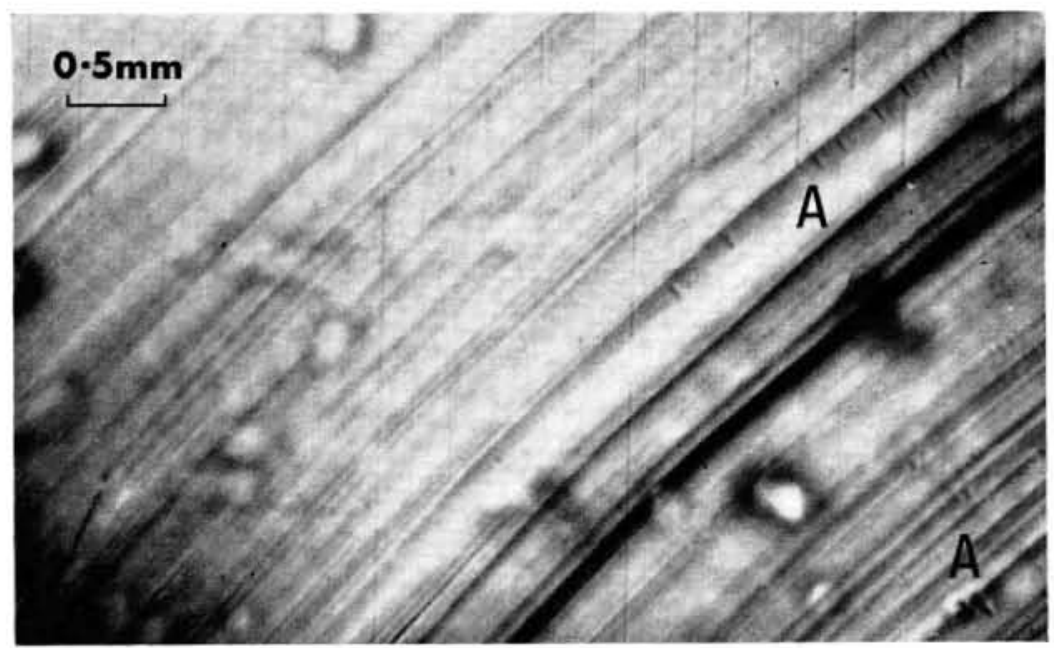

Fig. 5. Slip lines on the surface of a deformed ice crystal seen by direct observation. Note short lines normal to the main slip lines at $\mathrm{A}$. 
nence. This must mean that slip can only occur easily at certain places in the crystalpresumably where there are suitable sources to generate dislocations-and it also suggests that, although they probably start to generate dislocations at about the same time, these sources are not all equally effective.

In some cases the stress system caused the whole crystal to bend about an axis parallel to the direction of viewing. This may well have been a result of the sideways constraint applied by the metal caps to which the knife edges were attached. On other occasions the strain caused the slip bands themselves to curve as in Figure 5. When the curvature was sufficient, short slip lines perpendicular to the main ones appeared and some of these can also be seen in Figure 5 .

It is possible to interpret these short lines as tilt boundaries formed by dislocations which have their Burgers vectors parallel to the $a$-axis and lying in basal planes. Although this interpretation is quite consistent with the stress required to produce curvature, it is not at all clear why they should be visible because, unlike slip bands, they do not correspond to a step on the surface. A possible explanation is that since paraffin etches ice very slightly it could produce a visible groove in a region where there is a very high density of dislocations.

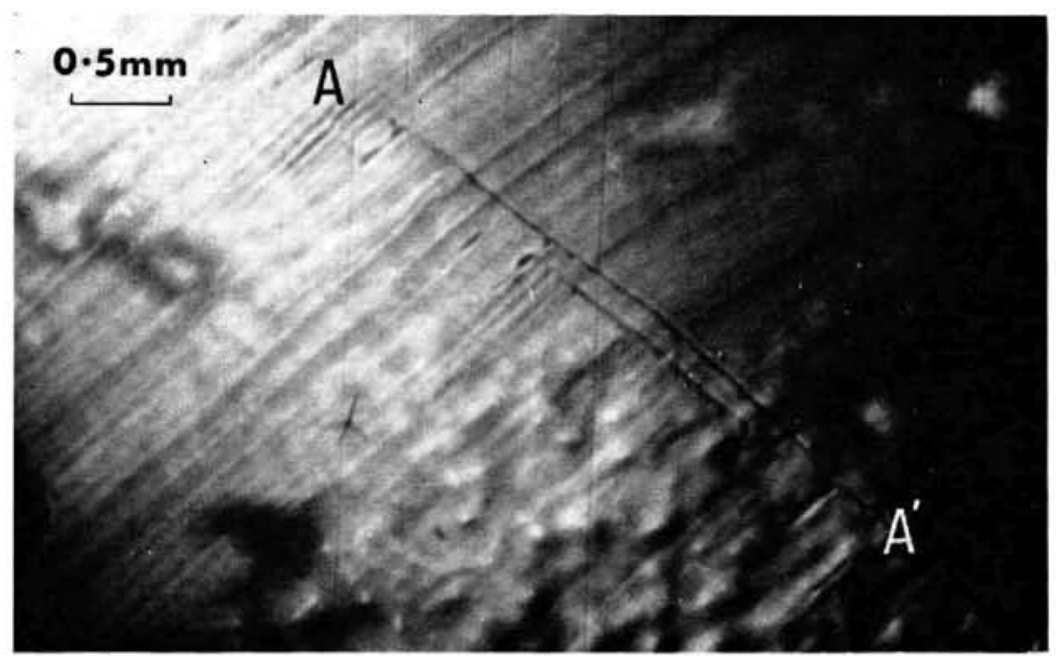

Fig. 6. Grain boundary formed by "Kinking" under applied stress. Note the groove, AA', on the surface where the grain boundary meets it.

\section{Formation of grain boundaries}

Sometimes the concentration of dislocations in a specimen became so large that it could no longer be accommodated by a continuous curvature of the lattice. When this happened a grain boundary was formed across which there was an abrupt change of orientation by several degrees. This could easily be detected by the change in the extinction position across the boundary. The localization of the deformation in this way is a type of "kinking", a phenomenon which has often been observed in ice (e.g. Higashi and Sakai, 196r). Nakaya (1958[b]) also found that the deformation was localized when he deformed single crystals by bending them.

A typical example of a grain boundary is shown in Figure 6 and although the boundary is straight in this case, many examples of curved or irregular boundaries were also seen. The photograph shows that there is considerable distortion of the slip lines close to the grain boundary and that there is a narrow groove where it meets the surface, which is probably another example of etching by paraffin in a region of high local strain. Nevertheless the slip 
bands are more or less continuous across the boundary and the change in their orientation is entirely consistent with the change in the extinction position as revealed by crossed polarizers. The continuity of the slip bands suggests that they were formed before the grain boundary and in fact we found that once a grain boundary had been formed the specimen usually bent rapidly at the boundary and finally collapsed under the load.

\section{Non-basal slip}

In a few cases we observed slip lines perpendicular to the basal plane even when there was no detectable curvature of the specimen and one of the best examples of this is shown in Figure 7 .

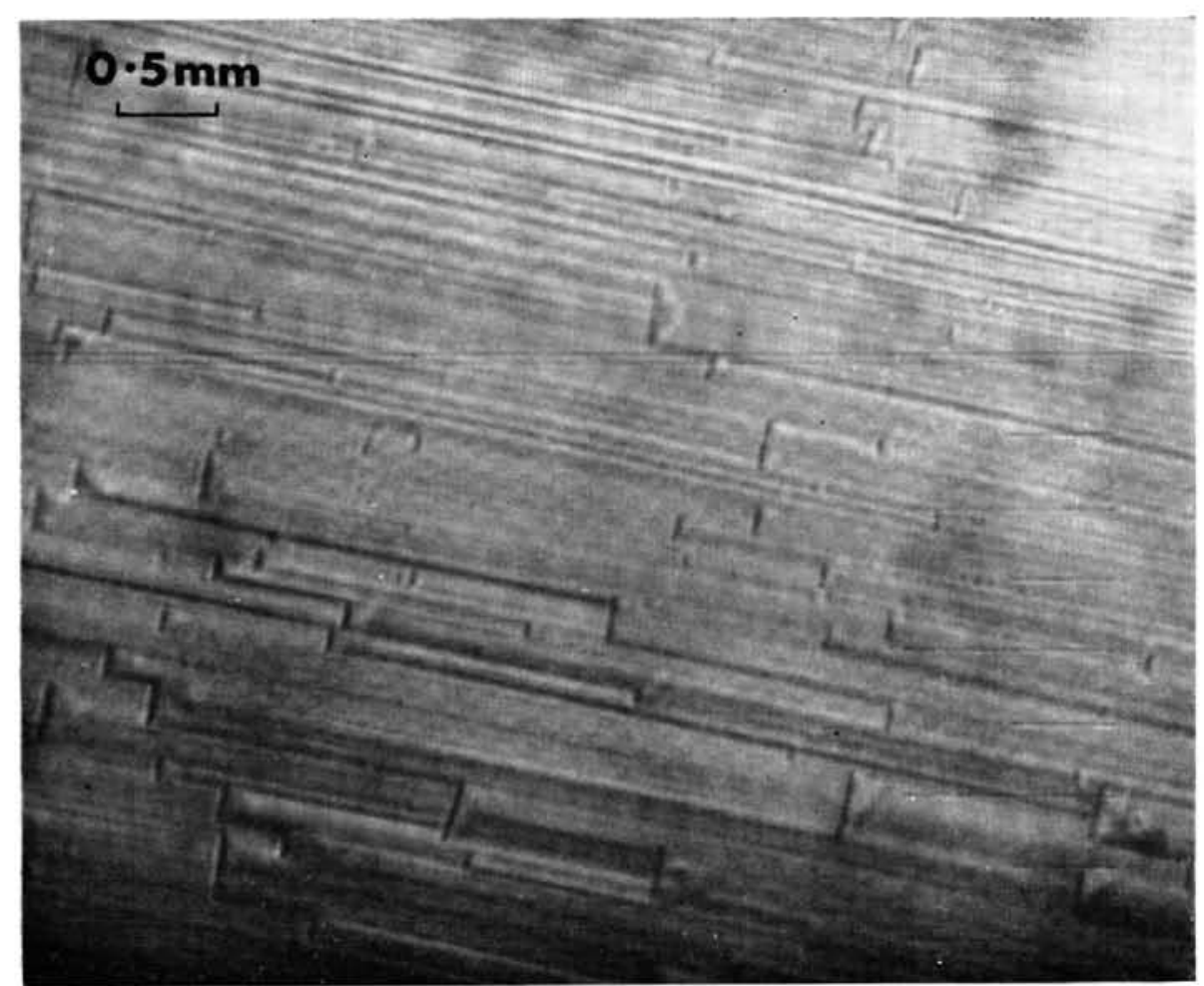

Fig. 7. Slip lines on the surface of a deformed ice crystal, showing segments perpendicular to the trace of the basal plane on the surface.

The segments of the slip lines perpendicular to the basal plane have quite a different appearance from those in Figure 4, but are very similar to the ones observed in polycrystalline ice by Gold $(1963)$. It can be seen from Figure 7 that there are pronounced zig-zag traces running across the specimen, which suggests that we are observing a type of cross-slip. Dislocations whose Burgers vectors are parallel to the $a$-axis, $\langle 2 \overline{\mathrm{i}} \overline{\mathrm{l}} \mathrm{\rangle}\rangle$, can glide on the basal plane and if they are in the screw orientation they can also cross-slip on the appropriate prism plane, $\{0 \mathrm{i} \overline{\mathrm{I}}\}$. Thus it seems reasonable to suppose that if glide on a particular basal plane becomes difficult due to various types of locks forming between gliding dislocations and forest dislocations, deformation may continue by cross-slip of the active dislocations on to another, more favourable, glide plane. If this happens for one dislocation, it may well occur for others produced in the same glide band, which would account for the observed slip traces. 
Although this mechanism involves slip on non-basal glide planes, it does not require dislocations with non-basal Burgers vectors. These observations accord very well with the work of Bryant and Mason ( 1960 ), who found sets of coaxial dislocation loops radiating from indentations on the basal plane of ice crystals. These dislocations also had their Burgers vectors parallel to the $a$-axes of the crystal, but were gliding on planes in the $\langle 2 \bar{i} \bar{i} 0\rangle$ crystallographic zones, such as $\{01 \overline{1} 0\}$ and $\{0001\}$.

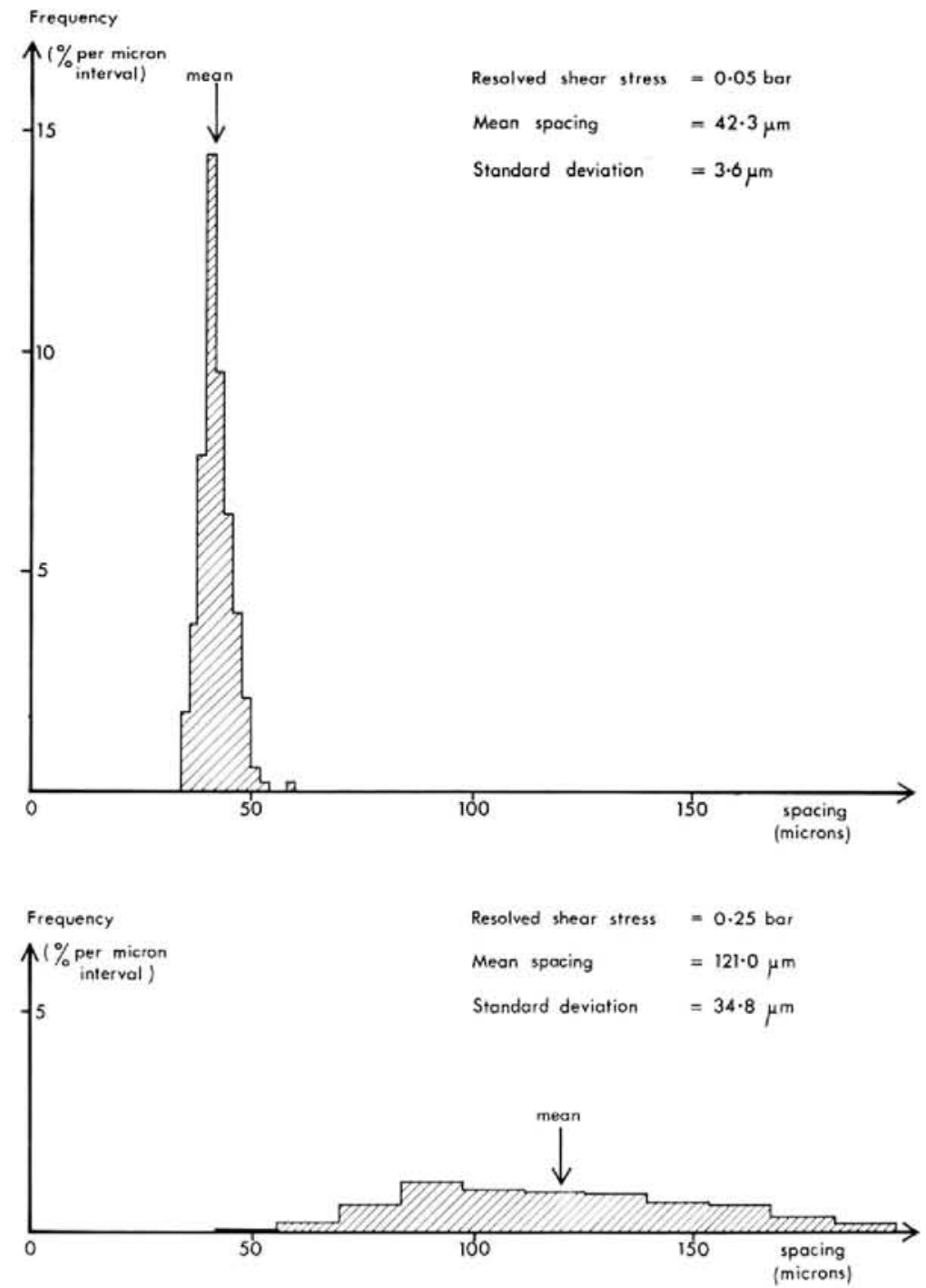

Fig. 8. Typical histograms showing frequency of occurrence of slip band spacings: (top) an example of fine slip (based on $1 \beta_{3}$ values); (bottom) an example of coarse slip (based on 387 values).

Other workers (e.g. Muguruma and Higashi, 1963; Levi and others, 1965) have given evidence for dislocations with non-basal Burgers vectors with orientations such as $\langle$ ooor $\rangle$ or possibly $\left\langle\mathrm{t}^{\mathrm{2}} 3\right\rangle$, but their existence is not demonstrated by this part of our work. However, some evidence for active dislocations with components of their Burgers vectors parallel to the $c$-axis will be presented in a later paper. 


\section{Slip band spacings}

The tcchnique for making "formvar" replicas as described above cnabled us 10 make accurate measurements of the spacing of the slip bands under the microscope. Histograms of the observed spacings of a few hundred bands on two typical specimens are shown in Figure 8. It may be noted that the distributions are not symmetrical and are not described by a simple law. It was also interesting to find that there was no delectable difference between specimens with a high organic carbon content and the others. For this reason no distinction will be made between the results obtained for different types of specimens.

The thicknesses of the slip lamellae were deduced from the observed spacings of the slip bands, allowing for the angle of inclination of the basal plane to the surface. In Figure 9 reciprocals of the means of the thicknesses of the lamellae arc plotted against the resolved shear stresses acting on the basal plane and the observed variation in the thicknesses of the lamellae is shown for each point on the graph.

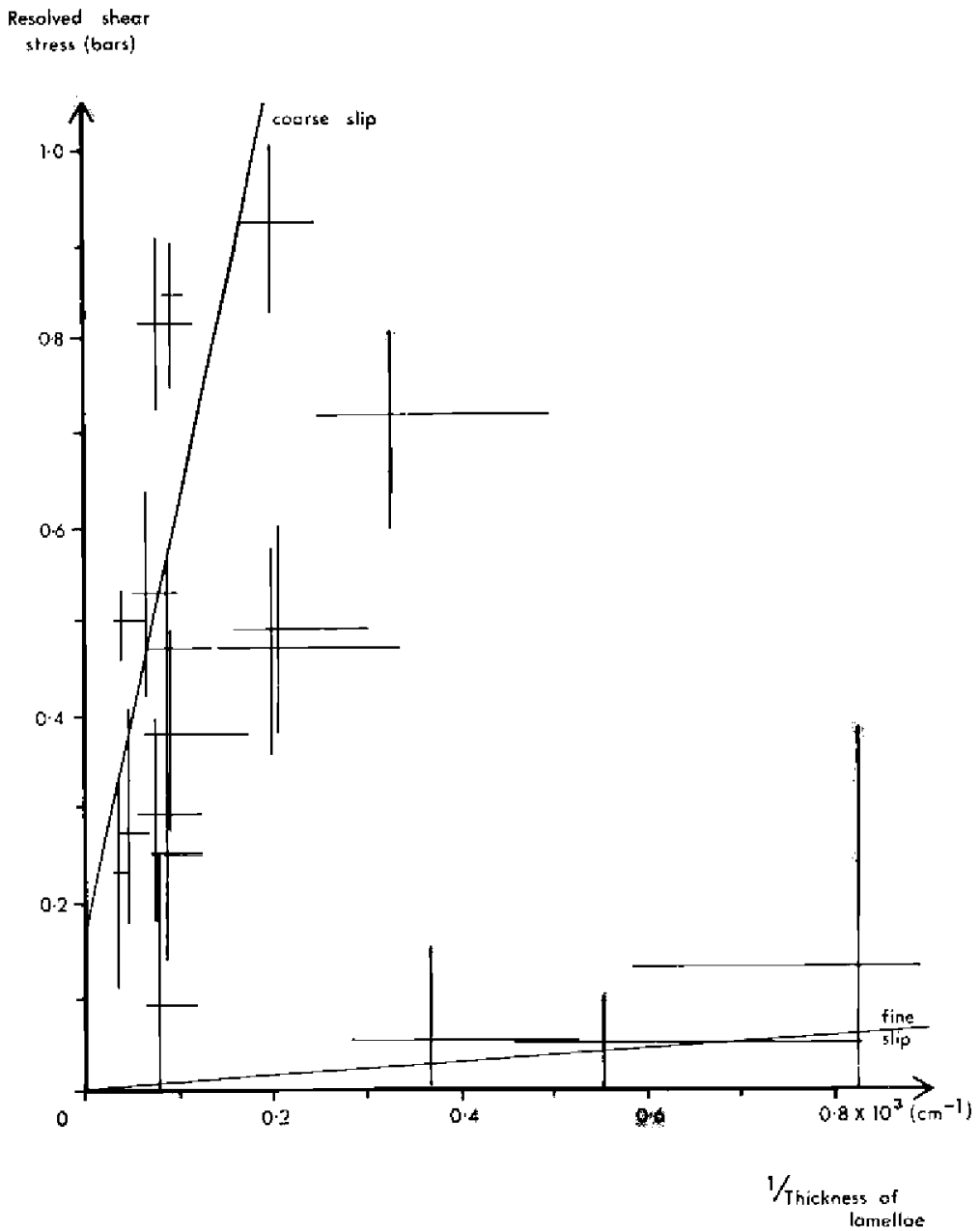

Fig. 9 . Variations in thicknesses of lamellae with the component of shen stress axting on the basal plane. 
Two theoretical relationships between the resolved shear stress $\sigma$ and the slip band spacing $d$ are represented by the straight lines on the graph. Wakahama's (1962) empirical relationship has the form

$$
(\sigma-0.2) d=0.45 \times 10^{-3}
$$

when $\sigma$ is measured in bars and $d$ is measured in centimetres. It agrees quite well with most of the results for stresses greater than about 0.2 bar, although the histograms show that Wakahama's assumption of uniform slip band spacings does not agree with theobservations. In this case there is a critical shear stress of about 0.2 bar below which no slip bands would be observed.

There are, however, a few cases in which very closely spaced slip lines were observed at low stresses. These do not agree at all with Wakahama's relationship but are close to Taylor's (1934) theory. He assumed that no critical shear stress was needed to move individual dislocations and deduced that for an array of dislocations

$$
\sigma d=0.16 G a
$$

where $G$ is the shear modulus and $a$ is the lattice parameter. Taking $G \approx 10^{4}$ bar and $a=4.5 \times 10^{-8} \mathrm{~cm}$ for ice (Dorsey, 1940) gives $\sigma d=7.2 \times 10^{-5}$ and it is interesting to see that this line passes very close to the otherwise anomalous points.

An interesting parallel to these results is provided by the work of Andrade and Roscoe (1937) on lead. When they examined the surface of a deformed lead crystal with a microscope they could easily see irregularly spaced slip lines. At higher magnification, however, more closely spaced slip lines became visible and these were much more evenly spaced. These two types of slip lines are generally referred to as "coarse slip" and "fine slip" respectively. Now it appears that only fine slip lines were present in our experiments when the resolved shear stress was below about 0.2 bar. At higher stresses and larger deformations both coarse slip and fine slip were probably present. However, substituting a stress of 0.2 bar into Taylor's relationship leads to a spacing of about $3 \mu \mathrm{m}$ for the fine slip lines and since this is near the limit of resolution of the optical microscope they could not be observed. Nevertheless it may be possible to observe both fine and coarse slip at higher stresses with the aid of carefully prepared "formvar" replicas and an electron microscope.

\section{Conclusions and Suggestions for Further Work}

The technique for growing single crystals of ice has been improved and, in particular, the problem of maintaining a low concentration of organic carbon seems to have been largely overcome. The residual carbon content could probably be reduced still further by using some new plastic materials to contain the specimens. It would also be easy to "zone refine" the crystals which we made by loading them into the growth apparatus instead of starting with polycrystalline ice.

It is now clear that some of the methods used in the past for making single crystals almost certainly led to the inclusion of large organic molecules in the ice and although these had no detectable effect on the deformation of single crystals, it is by no means certain that they would leave other properties equally unaltered.

The method used for the production of single crystals also makes it fairly easy to introduce definite amounts of known impurities, as Jaccard and Levi (196i) have already shown. For instance it would be interesting to dissolve some salts in the pure water from which the crystals are grown, since Truby (1955), found that traces of calcium fluoride had a marked effect on his results. It would also be interesting deliberately to include particles or air bubbles in some specimens and to compare their behaviour with that of crystals containing a very few particles, since ice in glaciers almost invariably contains particulate matter. 
Dipping the specimens in parallin made it possible to obtain a plastic replica of the surface of a deformed specimen without ctching or distortion. Both "coarse" and "fine" slip have becn obscrved-the latter only at low stress. It may be possible to use this technique in conjunction with the electron microscopc to see if fine slip also occurs at larger stresses when coarsc slip is present.

Unfortunately at the moment it is not possible to visualize a technique for making replicas of the surface of the same specimen at successive stages during its deformation in order to follow the development of slip bands during creep. However, it may be possible to make a set of specimens with identical orientations and to replicate their surfaces al different stages so as to build up a complete picture of the creep process. A series of such experiments at different temperatures may further elucidate the creep mechanism in ice.

This adds to the increasing body of evidence for slip on non-basal planes. In the present work, however, no systematic condition for non-basal slip was apparent, but it is to be hoped that further work will succeed in defining the conditions for non-basal slip more precisely.

\section{ACKNOWLEDGEMENTS}

We should like to thank Dr H. A. C. Montgomery for determining the concentration of organic carbon in our specimens and Dr G. P. Rigsby for supplying us with photographs of his universal stage. We are also grateful to Dr A. Thetford for advice and help in aluminizing the plastic replicas and to Dr B. J. Mason for his continued encouragement of this work. Finally, one of us (C.J.R.) would like to acknowledge the support of a D.S.I.R. Research Studentship.

MS. received 5 April 1968 and in revised form 16 May 1968

\section{REFERENGES}

Andrade, E. N. da $\mathrm{C}_{.,}$and Roscoe, R. I937. Glide in metal single crystals. Procedings of the Physical Societ.", Vol. 49, Pt. 2, p. $152-77$.

Bryant, G. W., and Mason, B. J. 1960 . Etch pits and dislocations in ice crystals. Philoxophical Magazine, Eighth Ser. Vol. 5. No. 6o, p. 1221-27.

Dorsey. N. E. 1940. Properties of ordinary water-substance in all its phases: waler-wapor, water and all the ices. New York, Reinhold Publishing Corporation. (American Chemical Society. Monograph Series, No. 81.)

G]en. J. W., and Pcrutz, M. F. 1954. The growth and deformation of ice crystals. Journal of Glaciology, Vol. 2; No. 16, p. $397-403$.

Gold, L. W. Ig63. Deformation mechanisms in ice. (In Kingery, W. D., ed. Ite and snawe; froperties, processes, and applications: procedings of a conference held at the Massachuselts Institute of Technolog, February 12-16, 1969 . Ciurtbridge, Mass., The M.I.'. . Press, p. 8-27.)

Higashi A. and Sakai, N. 1961. Movenent of small angle boundary of ice crystal. Joumal of the Physical Society of Japur, Vol. 16, No. 11, p. 2359-60.

Jaccard, C. I959. Etude théorique et expérimentale des proprićtés élertriques de la glace. Helzetica Physica Acta, Vol. 32 , Fasc. 2 , p. $89-128$.

Jaccard. C.. and Levi, I. Ig6. I. Segrégation d'impuretés dans la glace. Zeitschrif für angewandte Mathematik und Physik, Vol. 12. Fasc. 1, p. $7^{\mathrm{o}-7^{6}}$.

Levi. L.. and others. ${ }_{1965}{ }_{5}$. Experimental study of non-basal dislocinions in ice crystals, by L. Levi, E. M. de Achaval and F. Suraski. Journal of Claciology, Vol. 5. No. 41. p. 691-99.

McComel. J. C. I8go. On the plasticity of an ice crystal (preliminary note). Procedings of the Royal Society. Vol. 48 , No. 294, p. $259-60$.

McConnel. J. C. $189 \mathrm{I}$. On the plasticity of an ice crystal. Procedings of the Royal Sockty, Vol. 49. No. 299.

p. 323-43.
MrConnel. J. C., and Kidd. D. A. 1888 . On the plasticity of glacier and other ice. Frocedings of the Royal Society, Vol. 44. No. 270, p. $33^{3} 67$.

Montgomery, H. A. C.. and Thom, N. S. 1962 . The determination of low conecntrations of organic carbon in water. Araiysl, Vol. 87 . No. 1038. p. $689-97$.

Muguruma, J. I963. Etch pits on prisin planes of plast icalty deformed ice crystals. Jomot of the faculty of Scienee, Hokkaido University, Ser. 2, Vol. 6, No. I, p. $11-22$. 
Muguruma, J.. and Higashi, A. 1963. Non-basal glide bands in ice crystals. Nature. Vol. 198, No. 4880. p. 573.

Nakaya, U. 1958[a]. The deformation of single crystals of ice. Union Géodésique el Géophysique Internationale. Association Internationale d'Hydrologie Scientifique. Symposium de Chamonix. 16-24 sept. 1958. p. 229-40.

Nakaya. U. 1958|b]. Mechanical properties of single crystals of ice. U.S. Snow. Iee and Permafrost Research Establishment. Research Report 28.

Schaefer, V. J. ${ }^{2} 946$. The production of ice crystals in a cloud of supercooled water droplets. Science, Vol. 104, No. 2707 , p. $457-59$.

Steinemann, S. 1954. Results of preliminary experiments on the plasticity of ice crystals. Fournal of Glaciology, Vol. 2, No. 16, p. $404^{-13}$.

Taylor, G. I. 1934. The mechanism of plastic deformation of crystals. Part I theoretical. Proceedings of the Royal Society, Ser. A. Vol. 145. No. 855. p. $362-87$.

Truby, F. K. 1955. Hexagonal microstructure of ice crystals grown from melt. Fournal of Applied Physics. Vol. 26, No. 12 p. $1416-20$.

Wakahama, G. 1962. On the plastic deformation of ice. I-1V. Teion-kagaku: Low Temperature Science. Ser. A, [No.] 20, p. $57^{-1} 30$. 